\title{
Trialling seawater irrigation to combat the high nest temperature feminisation of green turtle Chelonia mydas hatchlings
}

\author{
Caitlin E. Smith ${ }^{1, *}$, David T. Booth ${ }^{2}$, Anne Crosby ${ }^{2}$, Jeffrey D. Miller ${ }^{3}$, \\ Melissa N. Staines ${ }^{2}$, Hayley Versace ${ }^{4}$, Christine A. Madden-Hof ${ }^{1}$ \\ ${ }^{1}$ World Wide Fund for Nature - Australia, Brisbane, QLD 4000, Australia \\ ${ }^{2}$ School of Biological Sciences, The University of Queensland, Brisbane, QLD 4067, Australia \\ ${ }^{3}$ Biological Research and Education Consultants, 446 Dearborn Avenue, Missoula, MT 59801, USA
}

${ }^{4}$ The Conflict Islands Conservation Initiative, Panasesa Island, Alotau, Milne Bay Province 211, Papua New Guinea

\begin{abstract}
Global increases in beach sand temperatures are predicted to skew hatchling sex ratios of marine turtle populations towards female bias. Currently, shade structures and freshwater irrigation are management strategies used to cool nest temperatures, but require resources that are limited at remote rookeries. Here, we report on a novel investigation that used seawater irrigation as a sand-cooling method. Various volumes of seawater were applied to sand to determine the optimal application required to lower sand temperatures at nest depth to produce malebiased sex ratios. We performed these experiments during the 2019-2020 nesting season at Heron Island on the southern Great Barrier Reef, Australia, and at Panasesa Island, Papua New Guinea. We found the amount of cooling at nest depth was site dependent and varied with the seawater irrigation regime used. At Heron Island, we used a one-off application of the equivalent of $120 \mathrm{~mm}$ of rainfall either as freshwater or seawater to the sand above incubating clutches $18 \mathrm{~d}$ after oviposition to determine whether this affected the hatching success of green turtle Chelonia mydas eggs. Both treatments had higher hatching success $(83.8 \pm 3.5 \%$ and $71.2 \pm 6.3 \%$, respectively, means $\pm \mathrm{SE}$ ) compared to control clutches $(63.5 \pm 6.0 \%)$. Our results indicate that a one-off application of seawater may be an effective management option for reducing nest temperatures during the sex-determining period of marine turtle clutches incubating in situ. Seawater irrigation could be used in areas where populations are at highest risk of feminisation caused by a hot drying climate where freshwater is not available for irrigation.
\end{abstract}

KEY WORDS: Conservation management - Sea turtle · Irrigation · Embryonic development . Watering

\section{INTRODUCTION}

Anthropogenically induced climate change has placed intense pressures on ecosystems around the world (Descamps et al. 2017). Many species have shifted their ranges, and changed their genotypes, growth, phenology and ecological relationships as a result of these pressures (Visser 2008, Nicotra et al. 2010, Chen et al. 2011, Seebacher et al. 2015, Mason

${ }^{*}$ Corresponding author: cs@wwf.org.au et al. 2019). The extent of latitudinal range shift in marine species suggests that many are more vulnerable to the effects of climate change than their terrestrial counterparts (Poloczanska et al. 2013, Reusch 2014). Marine turtles are heavily reliant on both marine and terrestrial ecosystems and are therefore subjected to a range of environmental and anthropogenic stressors (Hawkes et al. 2009). Sea level rise threatening suitable nesting habitat, fish-

(c) The authors and World Wide Fund for Nature - Australia 2021. Open Access under Creative Commons by Attribution Licence. Use, distribution and reproduction are unrestricted. Authors and original publication must be credited.

Publisher: Inter-Research · www.int-res.com 
eries bycatch, ghost net entanglement, coastal development, pollution, marine debris ingestion, harvesting by humans, and population feminisation are some of the threats facing the marine turtle population (Hamman et al. 2007, Fuentes et al. 2016, Schuyler et al. 2016, Alfaro-Shigueto et al. 2018, Jensen et al. 2018, Varela et al. 2019, Villa et al. 2019, Stelfox et al. 2020). Because marine turtles exhibit temperature-dependent sex determination (TSD), the sex of their offspring is irreversibly determined by temperatures experienced during the middle third of embryonic development, when the gonads differentiate. Clutches are typically female biased when exposed to higher temperatures, generally above $\sim 29^{\circ} \mathrm{C}$ (Yntema \& Mrosovsky 1980, Broderick et al. 2000, Wibbels 2003). The sex ratio of TSD species may be greatly altered by as little as a $1^{\circ} \mathrm{C}$ change in incubation temperature (Janzen 1994). For many populations around the world, the warming climate has pushed marine turtle hatchling sex ratios towards complete feminisation (Hays et al. 2014, Urban et al. 2014, Jensen et al. 2018). This feminisation process is predicted to cause a decline in the hatchling output and genetic diversity and eventually lead to population extinction (Witt et al. 2010, Hawkes et al. 2013, Jensen et al. 2018, Tanner et al. 2019, Blechschmidt et al. 2020). Therefore, we urgently need practical methods of cooling nest temperatures to a level that results in greater male hatchling production.

There are many environmental factors that influence the variation in sand temperature within and between nesting beaches. These include sand colour, level of shading provided by vegetation, beach orientation, prevailing wind direction, and rainfall events (Hays et al. 2001, Booth \& Freeman 2006, Wood et al. 2014, Esteban et al. 2018, Tilley et al. 2019, Staines et al. 2019, 2020). Rainfall is an efficient and natural sand coolant causing decreases in nest temperature that can result in an increase in male hatchling production (Houghton et al. 2007, Lolavar \& Wyneken 2015, Rivas et al. 2018, Staines et al. 2020, Laloë et al. 2021). In the face of climate change, the frequency and severity of rainfall events is predicted to increase; however, these events are set to be variable and interchangeable with long periods of dry drought conditions (IPCC 2019). Therefore, active intervention will most likely be required to combat the feminising effect of warming sand temperatures in many locations. Nesting sites closer to the equator are predicted be at higher risk of feminisation due to consistently high air temperatures resulting in little annual seasonal variation in sand temperatures, but this will vary with environmental factors on each nesting beach (Poloczanska et al. 2009, Fuentes et al. 2010, Esteban et al. 2016). Shaded hatcheries and freshwater irrigation have been widely used at rookeries around the world for several decades to cool incubating sand temperature (Blanck \& Sawyer 1981, Standora \& Spotila 1985, Higginson \& Vasquez 1989). However, artificial shade structures typically only decrease nest temperature by $1-2^{\circ} \mathrm{C}$ (Wood et al. 2014, Esteban et al. 2018, Reboul et al. 2021), which is often not enough to induce male hatchling production. Also, nesting sites predicted for complete feminisation are often remote and may lack the resources and infrastructure required to implement these common management strategies (Hill et al. 2015, Jourdan \& Fuentes 2015, Lolavar \& Wyneken 2015, Lolavar \& Wyneken 2021). Although seawater is ubiquitous at marine turtle nesting beaches and may be an effective way to cool beach sand, it has not been previously investigated as a potential mitigation strategy to combat high nest temperatures.

Marine turtle eggs are highly susceptible to moisture changes as they are porous and thus lose or take on water depending on the water content of the nest sand (McGehee 1990, Packard 1999, Pike \& Stiner 2007). On theoretical grounds, sea turtle embryos exposed to seawater should become dehydrated from osmotic water loss because the osmotic water potential ( -900 kPa; Ackerman 1997) of the embryo is less negative than that of seawater $(\sim-2500 \mathrm{kPa}$; Tomlinson 2004), and when individual green turtle Chelonia mydas eggs are surrounded by sand that has been moistened with $75 \%$ or $100 \%$ seawater, they rapidly dehydrate and die (Bustard \& Greenham 1968). Seawater inundation of marine turtle nests during high tides or storm surges can cause embryo mortality (Martin 1996, Foley et al. 2006, Pike \& Stiner 2007, Caut et al. 2010), but it is unknown whether embryo death is caused by drowning or osmotic water loss. However, some reports suggest tidally inundated clutches can hatch with no significant decrease in hatching success (Foley et al. 2006).

There have been only 2 experimental studies examining the effects of seawater on marine turtle egg hatching success (Bustard \& Greenham 1968, Limpus et al. 2020) and no studies have trialled seawater as a coolant for marine turtle nests, or used a combination of seawater and shading. It has been assumed that seawater will dehydrate eggs and decrease hatching success, as indicated by Bustard \& Greenham's (1968) experiments. Consequently, the use of seawater as a sand coolant has been over- 
looked or dismissed (Pike \& Stiner 2007). However, a recently published study found that no significant mortality occurred when clutches of loggerhead turtle Caretta caretta eggs were inundated by seawater for periods of less than $6 \mathrm{~h}$ partway $(20-80 \%)$ through development (Limpus et al. 2020). Therefore, it is possible that short-term seawater application to entire clutches within a nest during the sexdetermining period (SDP), currently described to occur during the second trimester, when the gonads are differentiating, will not result in significant embryonic death.

In this study, we examined the effectiveness of seawater irrigation at 2 green turtle nesting beaches, using: (1) different irrigation regimes to lower sand temperature, and (2) a one-off irrigation of seawater to test its impact on green turtle clutch hatching success. This study is part of a broader Turtle Cooling Program led by the World Wide Fund for NatureAustralia (WWF-Aus), which aims to provide scalable sand-cooling management strategies to mitigate the effects of climate-change-driven feminisation in low-latitude green turtle populations, in particular, remote nesting beaches with limited resources for rookery management.

\section{MATERIALS AND METHODS}

\subsection{Study sites}

Our primary study site was located on Heron Island $\left(-23.8416^{\circ}, 151.2498^{\circ}\right)$, a small coral sand cay on the southern Great Barrier Reef, $80 \mathrm{~km}$ off the coast of Gladstone, Queensland, Australia. The study took place during December 2019 and January 2020 in which the accumulated rainfall was $83 \mathrm{~mm}$, the minimum shaded air temperature $20.7^{\circ} \mathrm{C}$, the maximum temperature $31.7^{\circ} \mathrm{C}$, and the average temperature $27^{\circ} \mathrm{C}$ (values obtained from an automated weather station located on Heron Island: http://hirs-monitor02. hirs.science.uq.edu.au/). Heron Island is classed as a medium-density nesting site for green turtles (50300 nesting females per season) and also supports a lower density nesting of loggerhead turtles and was included because it is a long-term monitoring site for the southern Great Barrier Reef nesting population of green turtles (Limpus 2008a,b). An eggless irrigation experiment (without artificial shade) and an eggcontaining irrigation experiment were performed on Heron Island to assess the effectiveness of different irrigation regimes (eggless experiment) and the effect of seawater on embryo survival (egg experiment).
Both experiments were conducted on the eastern side of the island, behind the first dune, where disturbance by tourists was unlikely. Because these sites are used by nesting turtles (we frequently observed them constructing nests in this area), the sites were barricaded with fallen logs and driftwood to prevent possible disturbance to the experiments by naturally nesting females. Both sites were adjacent to Pisonia brunoniana trees that cast shadows over parts of the site in the early morning and late afternoon.

Our second study site was located on the southeastern side of Panasesa Island $(-10.7391,151.7259)$, part of the Conflict Island Group in the south-east of Papua New Guinea. The Conflict Island Group supports a medium nesting population of green turtles ( 380 nests annually) with low-density hawksbill turtle nesting as well. During the peak nesting season December-January), the average temperature varies between $26^{\circ} \mathrm{C}$ and $30^{\circ} \mathrm{C}$, and rainfall typically varies between 100 and $175 \mathrm{~mm}$ per month (https:// weatherspark.com/y/144529/Average-Weather-inAlotau-Papua-New-Guinea-Year-Round). This site was chosen because it is located closer to the equator than Heron Island, and is at a similar latitude to Raine Island, the largest green turtle nesting site in the world (Limpus 2008b). It is also representative of a remote, community-managed nesting beach. The beach orientation was east-facing. This experiment assessed the effectiveness of irrigation and shade on lowering sand temperature at nest depth in eggless experiments.

\subsection{Permits}

Experiments at Heron Island were performed under a Scientific Purposes Permit (PTU19-002377) issued by the Queensland Parks and Wildlife Service (QPWS) and had animal ethics approval from the University of Queensland's Animal Ethics Committee, approval number SBS/402/19/HERON ISLAND. Experiments on Panasesa Island were performed on private land that was not located in a governed conservation park area, and did not involve animals, so no permits or ethics approval was required to conduct this research.

\subsection{Eggless irrigation experiments}

The sand-cooling trials aimed to test various irrigation regimes using seawater and freshwater (Table 1). At both Heron and Panasesa Islands, 
Table 1. Treatments used on Heron Island and Panasesa Island for eggless irrigation experiments. The amount of water applied to each treatment is equal to the amount in $\mathrm{mm}$ spread over an $80 \mathrm{~cm}$ diameter circle

\begin{tabular}{|lccc|}
\hline Treatment & $\begin{array}{c}\text { Shade } \\
\text { or sun }\end{array}$ & $\begin{array}{c}\text { Seawater } \\
\left(\mathrm{l} \mathrm{d}^{-1}\right)\end{array}$ & $\begin{array}{c}\text { Freshwater } \\
\left(\mathrm{l} \mathrm{d}^{-1}\right)\end{array}$ \\
\hline Heron Island & & & \\
Control & Sun & 0 & 0 \\
$20 \mathrm{~mm} \mathrm{~d}^{-1}$ for 4 d & Sun & 10 & 0 \\
$20 \mathrm{~mm} \mathrm{~d}^{-1}$ for 7 d & Sun & 10 & 0 \\
$50 \mathrm{~mm} \mathrm{~d}^{-1}$ for 1 d & Sun & 25.1 & 0 \\
$50 \mathrm{~mm} \mathrm{~d}^{-1}$ for 4 d & Sun & 25.1 & 0 \\
$50 \mathrm{~mm} \mathrm{~d}^{-1}$ for 7 d & Sun & 25.1 & 0 \\
$100 \mathrm{~mm} \mathrm{~d}^{-1}$ for 1 d & Sun & 50.2 & 0 \\
$100 \mathrm{~mm} \mathrm{~d}^{-1}$ for 4 d & Sun & 50.2 & 0 \\
$200 \mathrm{~mm} \mathrm{~d}^{-1}$ for 1 d & Sun & 100.4 & 0 \\
Panasesa Island $_{\text {Control }}$ & Sun & 0 & 0 \\
$50 \mathrm{~mm} \mathrm{~d}^{-1}$ for 4 d & Sun & 25.1 & 0 \\
$50 \mathrm{~mm} \mathrm{~d}^{-1}$ for 4 d & Sun & 0 & 25.1 \\
Control & Shade & 0 & 0 \\
$50 \mathrm{~mm} \mathrm{~d}^{-1}$ for 4 d & Shade & 25.1 & 0 \\
$50 \mathrm{~mm} \mathrm{~d}^{-1}$ for 4 d & Shade & 0 & 25.1 \\
\hline
\end{tabular}

iButton $^{\mathrm{TM}}$ temperature data loggers (model DS1922L-F5, Maxim Integrated, resolution $=0.0625^{\circ} \mathrm{C}$, accuracy $\pm 0.1^{\circ} \mathrm{C}$ ) were buried at nest depth, $\sim 70 \mathrm{~cm}$, and programmed to record sand temperature every hour from 2 to 19 December 2019 at Heron Island and from 8 to 17 November 2019 at Panasesa Island. The data loggers were buried by excavating a $70 \mathrm{~cm}$ deep hole using $10 \mathrm{~cm}$ diameter PVC pipe hammered into the sand with a rubber mallet. A cap was then placed over the unburied end to seal the pipe and allow a core of sand to be removed. Data loggers were then enclosed in rubber balloons to protect against water, attached to the end of a cord (to aid in data logger retrieval), and lowered into the hole. The hole was then refilled with the sand removed in the PVC pipe to keep the sand's structure and minimise the time needed for sand temperature to stabilise (Laloë et al. 2016). The location of the data logger was marked by a stake labelled with the treatment and triplicate number. Treatment areas were spaced $1 \mathrm{~m}$ apart to allow for an $80 \mathrm{~cm}$ diameter water application area. The time and date of data logger burial were recorded. Each irrigation regime was replicated 3 times.

At Heron Island, water for each treatment was collected from the sea within $10 \mathrm{~m}$ of the shore line between 18:00 and 20:00 $\mathrm{h}$ the day prior to its application, and stored in $60 \mathrm{l}$ rectangular containers (60 $\times$ $40 \times 25 \mathrm{~cm}$, length $\times$ width $\times$ height) overnight at the experimental site to allow the water to decrease in temperature in order to maximise the water's cooling capacity. Water was applied to sites between 05:00 and 05:30 $\mathrm{h}$ before sunrise and its temperature was recorded with a digital thermocouple immediately before it was used. Immediately before water application, an $80 \mathrm{~cm}$ diameter (surface area $=5030 \mathrm{~cm}^{2}$ ) circular loop made from $2.5 \mathrm{~cm}$ diameter plastic irrigation pipe was placed on top of the area to be watered and 2 rain gauges were placed within this loop. A 91 watering can was used to apply the water to the loop area by pouring the water from the can through its sprinkler head while moving the can over the site in a slow continuous circular motion. Typically, between 1 and 5 min were required to apply the water, depending upon the volume of water applied. Two days after the end of the last water application, data loggers were recovered and the sand temperature data were downloaded.

The ' $50 \mathrm{~mm} \mathrm{~d}^{-1}$ for $4 \mathrm{~d}$ ' treatment was replicated on Panasesa Island, and both seawater and freshwater were used in different treatments, with and without shade (Table 1). Space availability precluded replication of other treatments. Each treatment had 6 replicates, giving a total of 36 simulated nests. Similarly to Heron Island, water was collected in the evening and left to cool overnight to achieve the lowest possible temperature. Each watered treatment received $25 \mathrm{l}$ of water (seawater or freshwater) over an $80 \mathrm{~cm}$ diameter area (surface area $=5030 \mathrm{~cm}^{2}$ ), delivered via a $9 \mathrm{l}$ watering can between 05:00 and 07:00 h per day over $4 \mathrm{~d}$. The shade structure used on Panasesa was made from naturally occurring palm fronds and provided $100 \%$ shade, although gaps between the fronds allowed for natural rainwater to reach the sand below. The shade structure was located on the beach slope and had dimensions of $4 \times$ $7 \mathrm{~m}$ with a height of $2 \mathrm{~m}$. The sun-exposed site was located immediately to the southern side of the shade structure, with both the shade and sun sites parallel to the beach, $10 \mathrm{~m}$ from the high tide line.

\subsection{Green turtle clutch irrigation}

Twelve clutches of green turtle eggs were collected over 4 nights ( 3 clutches per night) on Heron Island, starting on 1 December 2019, and one-third of each clutch was assigned to 1 of 3 treatments: control, freshwater irrigation, and seawater irrigation. On each of the 4 nights, the beach was patrolled to locate nesting females in oviposition. The female's flipper tag was recorded, and egg collection began after she had laid approximately 20 eggs. The collection continued until the female had finished laying. 
Collected eggs were placed in a bucket, walked to the artificial nest location site, and left there until 3 clutches had been collected. Each clutch was counted to record the total number of eggs laid and then split into 3 equal groups. One of these groups was combined with the eggs from the other 2 clutches to form a new 'artificial nest'. Each artificial nest was dug to a depth of $70 \mathrm{~cm}$, and the eggs from each clutch placed into it were separated from each other by plastic gutter-guard mesh (mesh size $5 \mathrm{~mm}$ in diameter) so the eggs were in contact with each other, but the clutches were kept separate to allow identification of the clutch of origin after hatching. Each clutch had a ping pong ball marked with the clutch code and female tag number placed amongst the eggs so the 3 separated clutches could be identified when the nest was excavated at the end of incubation. The time of egg relocation was recorded, and an iButton ${ }^{\mathrm{TM}}$ temperature data logger, recording nest temperature every hour, placed inside a $60 \mathrm{ml}$ specimen jar was positioned in amongst the eggs before the nest hole was filled with sand. All egg relocation and artificial nest set-up procedures were completed within $2 \mathrm{~h}$ of the collection of the first clutch of eggs.

To summarise, 3 artificial nests were set up each night over 4 consecutive nights, with one artificial nest from each night assigned to the control, seawater irrigation, or freshwater irrigation treatments (Fig. 1). On day 18 of incubation, 50.21 of freshwater or seawater, an equivalent of $100 \mathrm{~mm}$ of rain, was applied to the respective treatment nests by the method described above for eggless experiments. Day 18 of incubation was chosen for irrigation as this was estimated to be at the beginning of the SDP. Seawater was obtained from the sea and left overnight as described for the irrigation experiments. Freshwater was obtained from Heron Island Research station, transported to the artificial nest site, and left overnight in $60 \mathrm{l}$ containers as described for seawater. Two rain gauges were placed above the experimental nests to record the exact amount of water (sea or fresh) sprinkled on each nest. Water was applied immediately after temperature was recorded using a digital thermocouple, as described for the irrigation experiments. From 26 January 2020 onwards, experimental nests were visited daily to check for hatchling emergence. Nest excavation occurred 1 or $2 \mathrm{~d}$ after hatchling emergence. The hatching and emergence success of each clutch within each experimental nest was recorded by counting the number of empty shells and unhatched eggs in each section of the nest (Wyneken et al. 1988). All unhatched eggs were opened, and the developmental stage of

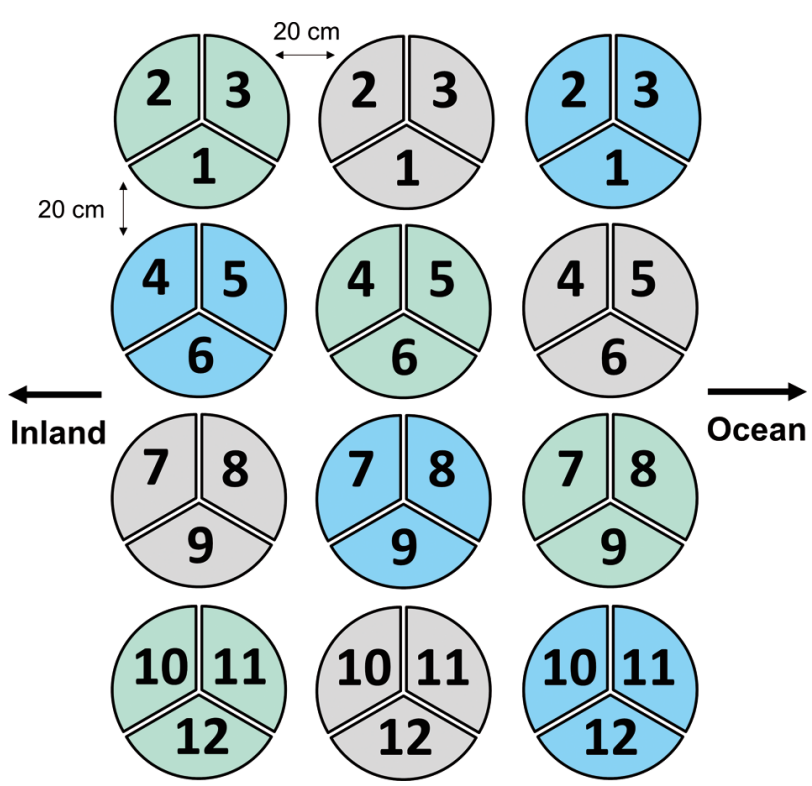

Fig. 1. Experimental design of the irrigation of green turtle eggs. Each pie diagram represents a nest composed of eggs from 3 separate clutches. Clutch origins are numbered 1-12, and each colour depicts 1 of 3 treatments: grey = control, blue $=$ freshwater irrigated, green $=$ seawater irrigated . Each treatment replicate was set up on 1 of 4 consecutive nights, corresponding to the 4 rows. Centres of nests were separated by $80 \mathrm{~cm}$. Diagram is not to scale

embryos was classified into the 6 phases described by Dunstan \& Robertson (2017) (Fig. 2).

\subsection{Predictive sex-ratio modelling}

We used data on the relationships between constant incubation temperature and incubation period and hatchling sex ratio gathered from published reports (Bustard \& Greenham 1968, Miller \& Limpus 1981, Booth \& Astill 2001, Booth et al. 2004, Burgess et al. 2006) for the southern Great Barrier Reef population of green turtles to formulate predictive nonlinear algorithms for the relationship between incubation temperature and embryonic development rate and hatchling sex ratio (see Text S1, Figs. S1 \& S2 in the Supplement at www.int-res.com/articles/suppl/ m667p177_supp.pdf). We then used individual hourly nest temperature traces and the developmental rate algorithm to predict the SDP for each nest, which was assumed to occur during the middle third of embryonic development (Booth \& Freeman 2006). We then calculated the constant temperature equivalent (CTE; Georges et al. 1994) during the SDP for each nest and used the CTE to calculate the predicted hatchling sex ratio for each nest from the relationship 


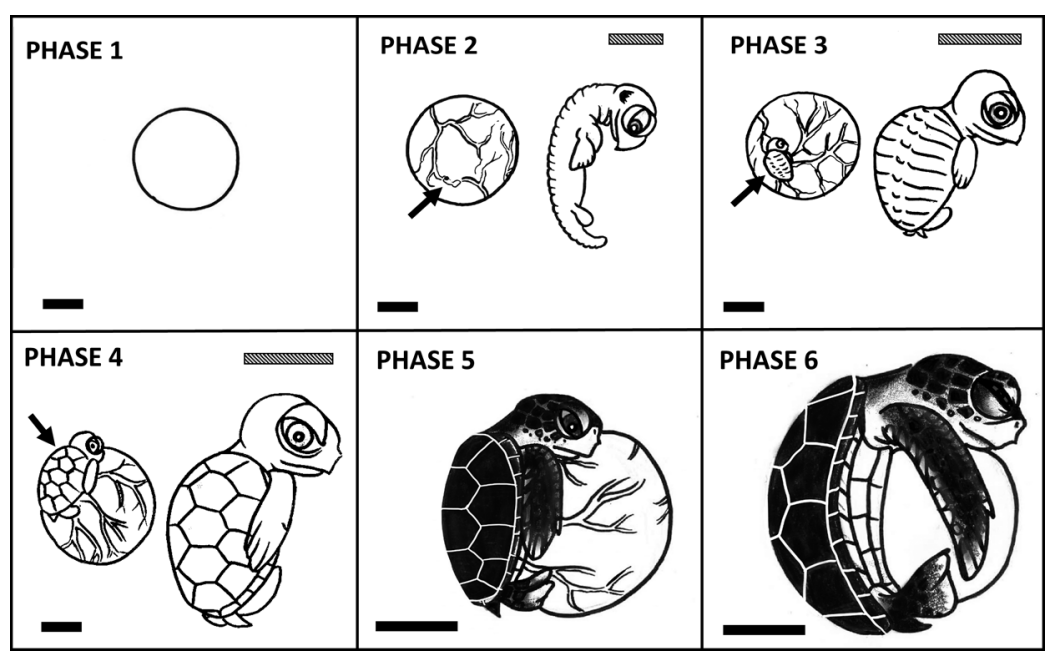

Fig. 2. Diagrams of the 6 different phases of development of marine turtle embryos identified in Dunstan \& Robertson (2017), which are based on the more detailed stages described by Miller et al. (2017). Stages refer to Miller et al. (2017). Phase 1 (stages 6-16): no visible development and no sign of red or pink pigmentation. Phase 2 (stages 17-21): limb buds present. Phase 3 (stages 22-23): carapace present, but no scutes on carapace. Phase 4 (stages 24-26): carapace scutes present, no scales on head or flippers. Phase 5 (stages 27-28): head and flipper have scales, yolk bigger than embryo. Phase 6 (stages 29-32): embryo fully formed, but yolk smaller than embryo. Arrows in phases 2,3 and 4 indicate location of the embryo on the yolk. Black scale bars = $10 \mathrm{~mm}$, and refer to yolk size in phases 2, 3 and 4 . Grey scale bars $=1 \mathrm{~mm}$ in phase 2, $5 \mathrm{~mm}$ in phase 3 , and $10 \mathrm{~mm}$ in phase 4 , and refer to the size of the embryo in each phase. Drawings by Melissa Staines

between incubation temperature and the proportion of female hatchlings produced at different temperatures (Text S1).

\subsection{Statistical analysis}

A mixed-model ANOVA where clutch was a random factor and irrigation treatment a fixed factor was used for analysis of arcsine-transformed hatching success data after testing for normality and homogeneity of variance using Levene's test. A post hoc Tukey's multiple comparison test was used to identify differences between treatment groups. Data are presented as means $\pm \mathrm{SE}$ and statistical significance is assumed if $\mathrm{p}<0.05$. All statistical analyses were performed using Statistica ${ }^{\circledR}$ Version 13.2 Software (Dell).

\section{RESULTS}

\subsection{Eggless irrigation experiments}

Nearshore seawater temperature at Heron Island averaged $29.6 \pm 0.1^{\circ} \mathrm{C}(\mathrm{n}=33)$ when it was collected in the evening, but had cooled by $4.5^{\circ} \mathrm{C}$ to $25.1 \pm 0.1^{\circ} \mathrm{C}(\mathrm{n}=33)$ by the time it was applied to the sand before sunrise the following morning. In Heron Island eggless experiments, the majority of temperatures at nest depth experienced an increase of $0.1-0.5^{\circ} \mathrm{C}$ (Fig. 3a-c, e-g) after the surface sand was irrigated, despite the temperature of the seawater $\left(25.1 \pm 0.1^{\circ} \mathrm{C}\right.$, range $23.6^{\circ} \mathrm{C}$ to $26.4^{\circ} \mathrm{C}$ ) applied to experimental plots being consistently cooler than that of the sand at nest depth (range $27.0^{\circ} \mathrm{C}$ to $27.8^{\circ} \mathrm{C}$ ) at the time of application (Fig. 3). The ' $200 \mathrm{~mm} \mathrm{~d}^{-1}$ for $1 \mathrm{~d}$ ' regime was the only treatment that resulted in a significant decline in sand temperature at nest depth $\left(\sim 1.5^{\circ} \mathrm{C}\right)$ immediately after application and regained its original temperature within $4 \mathrm{~d}$ (Fig. 3h). All Heron Island eggless irrigation regimes had consistently higher temperatures than the control triplicates throughout the experimental period (Fig. 3).

On Panasesa Island, the sand temperatures recorded in the shaded treatment were initially higher than that of sand temperatures in the unshaded treatment for the $4 \mathrm{~d}$ prior to irrigation, although they fell continuously from $28.6^{\circ} \mathrm{C}$ to $28.1^{\circ} \mathrm{C}$ before the onset of irrigation on day 4 , which also coincided with a natural rainfall event (Fig. 4). There was no difference in the cooling effect of freshwater and seawater. After irrigation began on day 4 , shaded irrigated sand temperatures decreased on average by $0.9^{\circ} \mathrm{C}$ by the end of irrigation on day 8 , while the shaded control (no irrigation) decreased by $0.6^{\circ} \mathrm{C}$ (Fig. 4). After irrigation began on day 4 , sun-exposed irrigated sand temperatures decreased on average by $0.8^{\circ} \mathrm{C}$ by the end of irrigation on day 8 , while the sun-exposed control decreased by $0.5^{\circ} \mathrm{C}$ (Fig. 4). To summarise, the lowest sand temperatures were recorded in the shaded irrigation treatment, the irrigated sun-exposed treatment had intermediate temperatures, and the sun-exposed treatment had the highest temperatures (Fig. 4).

\subsection{Green turtle clutch irrigation}

The application of seawater (mean $\pm \mathrm{SE}, 24.2 \pm$ $0.1^{\circ} \mathrm{C}$, range $\left.=24.0-24.3^{\circ} \mathrm{C}\right)$ and freshwater $(24.4 \pm$ $0.1^{\circ} \mathrm{C}, 24.3-26.3^{\circ} \mathrm{C}$ ) resulted in an immediate $1.3^{\circ} \mathrm{C}$ 

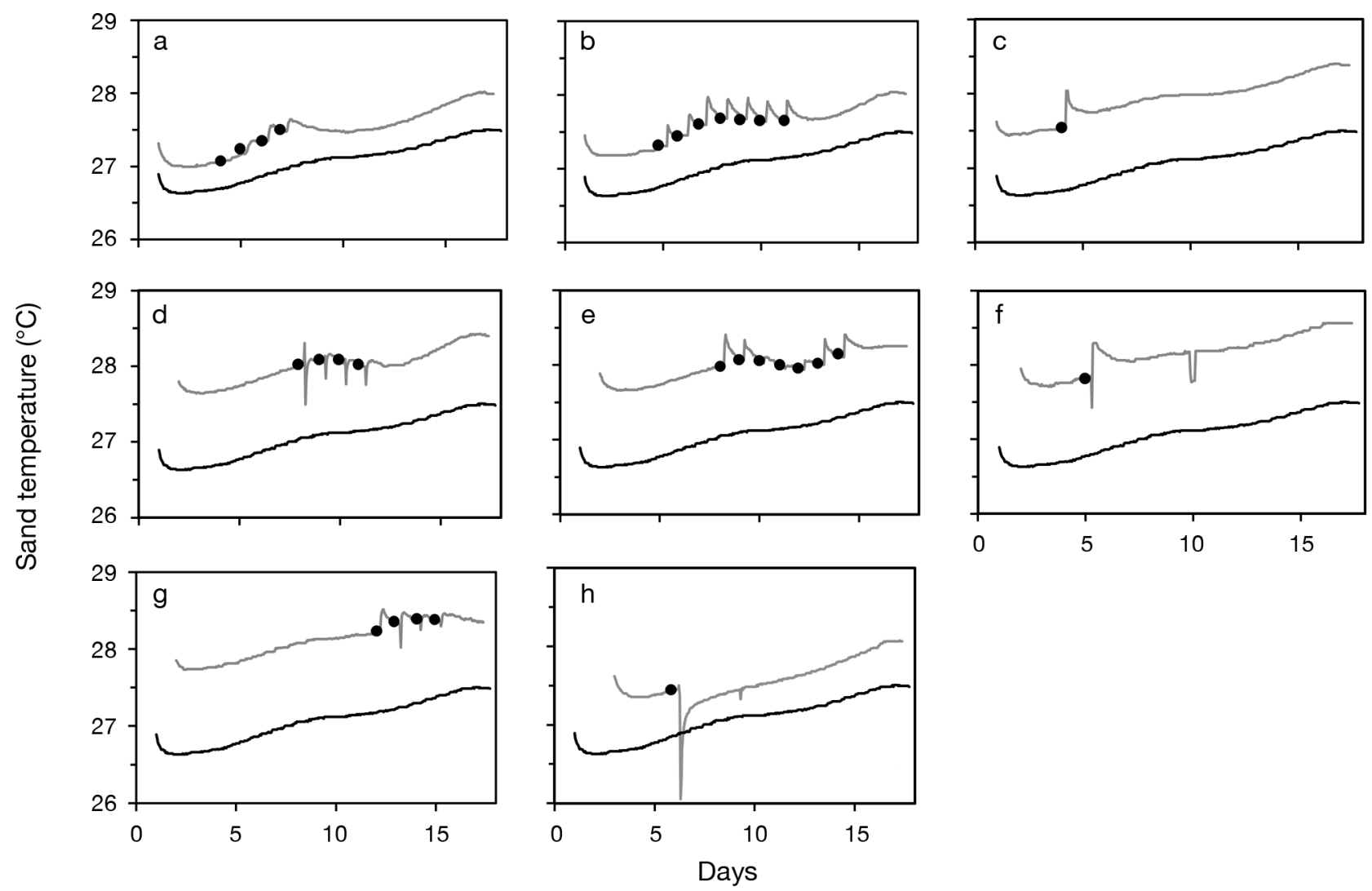

Fig. 3. Line trace of hourly sand temperatures at nest depth $(70 \mathrm{~cm})$ recorded over an $18 \mathrm{~d}$ period for the different eggless irrigation regimes performed during 2-19 December 2019 on Heron Island. Each panel represents an irrigation treatment: (a)

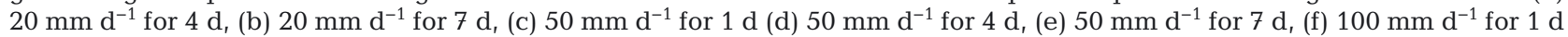
(g) $100 \mathrm{~mm} \mathrm{~d}^{-1}$ for $4 \mathrm{~d}$, and (h) $200 \mathrm{~mm} \mathrm{~d}^{-1}$ for $1 \mathrm{~d}$. Grey lines represent the mean temperature of 3 replicates used within each irrigation regime. The mean of the 3 control treatment temperature traces is represented by a solid black line. Solid black dots represent the time point at which irrigation took place. Column 1 represents data from the 4 consecutive day treatments, column 2 represents data from the 7 consecutive day treatments, and column 3 represents data from the one-off irrigation treatments. Note that after water was applied, the sand temperature at nest depth could either increase or decrease depending on the volume of water applied

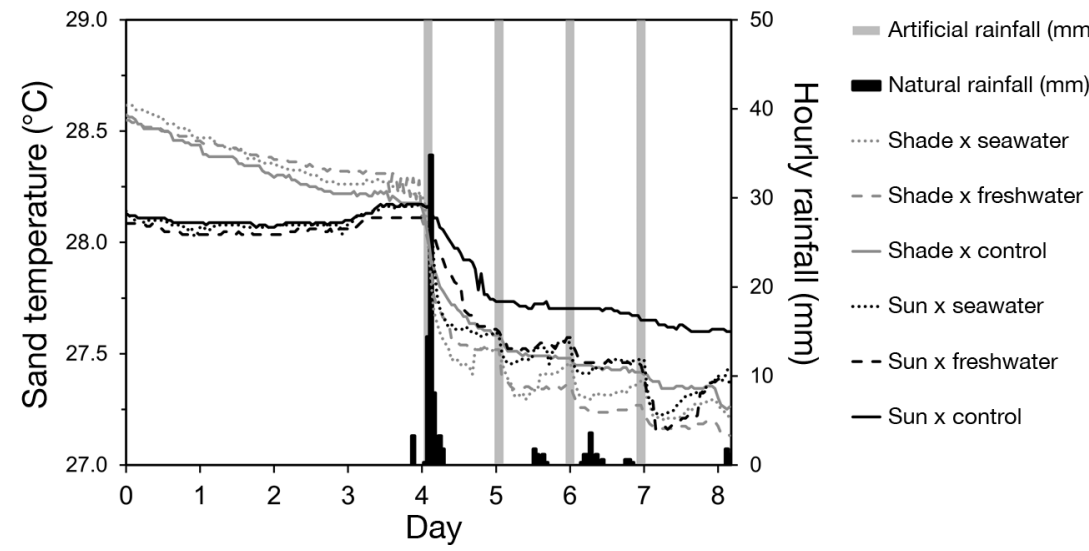

Fig. 4. Sand temperature variations at nest depth when freshwater and seawater were applied to both full sun-exposed and shaded plots on Panasesa Island, Papua New Guinea, 8-17 November 2019. Vertical bars indicate amount of water added to plots, either as natural rainfall (black) or as artificial watering (grey). Sand temperatures decreased the most after a large natural rainfall event on day 4 of the experiment drop in the average nest temperature from $28.2^{\circ} \mathrm{C}$ to $26.9^{\circ} \mathrm{C}$ and took $4 \mathrm{~d}$ to return to baseline nest temperature, while control nest temperatures remained constant (Fig. 5). Although we attempted to keep the amount of artificial rain applied to each experimental nest consistent, rain gauges recorded a small variation in amount of water applied $(128 \pm 1.26 \mathrm{~mm}, 100-$ $130 \mathrm{~mm})$.

During the SDP, nest temperature increased from $28.2^{\circ} \mathrm{C}$ to $31.5^{\circ} \mathrm{C}$, and by the end of incubation, nest temperatures reached between $35.0^{\circ} \mathrm{C}$ and $36.4^{\circ} \mathrm{C}$ (Fig. 5). Daily natural rainfall experienced (1-25 $\mathrm{mm} \mathrm{d}^{-1}$ ) during the experimental period did not result in 


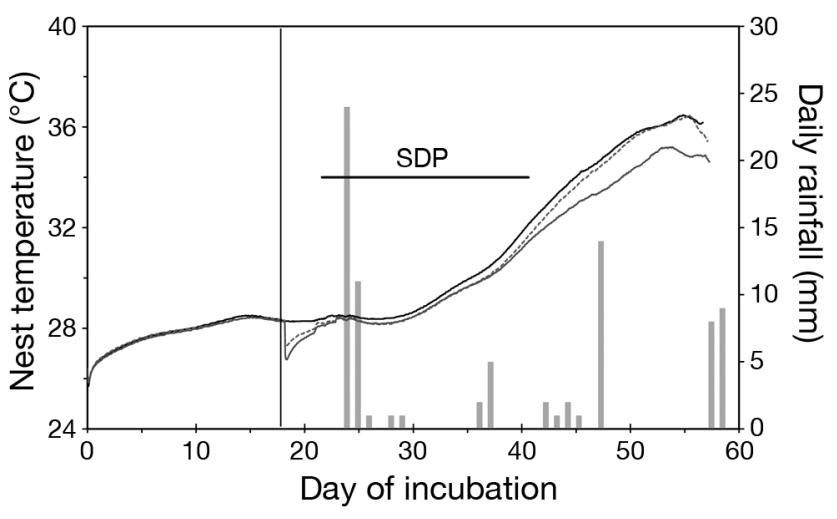

Fig. 5. Line traces of average hourly nest temperatures recorded in green turtle nests for each treatment throughout incubation. Each curve shows the average temperature of the 4 replicates of each treatment: control (solid black line), seawater irrigation (dashed grey line), freshwater irrigation (solid grey line). Vertical grey bars indicate daily natural rainfall data from Heron Island research station located $400 \mathrm{~m}$ away from the study site. The vertical line indicates when either freshwater or seawater was applied on day 18 of incubation. Based on a temperature-dependent incubation development rate model (Booth \& Freeman 2006), the thick black horizontal line indicates where the sex-determining period (SDP) would have occurred (days 22-42). Irrigation caused a temperature drop of $1.3^{\circ} \mathrm{C}$, but natural rain

fall was not great enough to influence nest temperature

significant decreases in experimental nest temperatures (Fig. 5).

When including all stages of embryonic death, the hatching success of control, seawater irrigated, and freshwater irrigated eggs were $63.5 \pm 6.0 \%, 71.6 \pm$ $6.3 \%$, and $83.8 \pm 3.5 \%$, respectively ( $\mathrm{n}=4$ for all treatments). Embryos in each treatment had a similar rate of mortality in phases 1 through 5 (control: $3.2 \pm$ $1.4 \%, 0-8.1 \%$; seawater: $3.1 \pm 1.4 \%, 0.2-8.1 \%$; freshwater: $1.9 \pm 1.6 \%, 0-8.0 \%$ ), but embryos in the freshwater treatment experienced the lowest proportion of mortality during phase $6(6.8 \pm 3.0,0-14.4 \%)$ (Table 2).

Because irrigation occurred after phases 1 and 2 of development, any deaths that occurred during these phases were not attributable to the application of water during irrigation. Hence, when assessing the effect of irrigation on hatching success, we have reported the hatching success excluding the deaths that occurred during phases 1 and 2 of development. After this adjustment, the hatching successes were $74.9 \pm 6.2 \%, 79.3 \pm 5.9 \%$ and $92.4 \pm 2.5 \%$, respectively, for control, seawater irrigation, and freshwater irrigation ( $\mathrm{n}=4$ for all treatments). A 2-way mixedmodel ANOVA showed that treatment significantly affected hatching success ( $p=0.006$; Table 3 ). The post hoc Tukey's test indicated there was a marked difference in hatching success between the control and freshwater irrigation treatment (control $=74.9 \pm$ $6.2 \%$, freshwater $=92.4 \pm 2.5 \%, p=0.018$ ) . However, there was no difference between the hatching success of the seawater and the control treatments, nor between the seawater and freshwater treatments ( $p>0.05$ in both cases). Hatching success was also not affected by clutch origin (Table 3 ).

\subsection{Predictive sex-ratio modelling}

Modelling using the temperature traces in Fig. 5 predicted CTEs for the sex determining periods of $29.0^{\circ} \mathrm{C}, 28.7^{\circ} \mathrm{C}$, and $28.7^{\circ} \mathrm{C}$ for the control, freshwater irrigation, and seawater irrigation treatments, respectively, which corresponds to $0 \%, 0 \%$ and $0 \%$ male hatchling production, if the SDP began on day 18 of the temperature traces. We ran multiple models with differing incubation start dates to determine if an earlier oviposition date would have changed the primary sex ratio of the clutches. In contrast, if the SDP had started on day 10 of the temperature traces, when sand temperatures were cooler, the CTE temperature predictions for the SDPs were $28.4^{\circ} \mathrm{C}, 28.1^{\circ} \mathrm{C}$, and $28.1^{\circ} \mathrm{C}$ for the control, freshwater irrigation, and seawater irrigation treatments, respectively, which corresponds to $2 \%, 64 \%$ and $64 \%$ male hatchling production. To summarise, according to sex-ratio

Table 2. Green turtle Chelonia mydas embryonic mortality (mean $\pm \mathrm{SE}$; \%) during each of the 6 phases of embryonic development for each of the 3 experimental treatments. Each treatment was replicated 4 times, and each replicate contained eggs from 3 different clutches, so that each treatment contained eggs from 12 clutches. ${ }^{*}$ Indicates a significant difference $(\alpha=0.05)$ identified with a post hoc Tukey's test

\begin{tabular}{|c|c|c|c|c|c|c|}
\hline \multirow{2}{*}{ Treatment } & \multicolumn{6}{|c|}{ Phase of embryonic development } \\
\hline & 1 & 2 & 3 & 4 & 5 & 6 \\
\hline Control & $10.0 \pm 4.5$ & $3.7 \pm 1.0$ & $0.0 \pm 0.0$ & $1.0 \pm 0.6$ & $3.3 \pm 1.4$ & $18.0 \pm 4.4^{*}$ \\
\hline Seawater & $7.6 \pm 3.2$ & $2.3 \pm 0.8$ & $0.3 \pm 0.3$ & $0.5 \pm 0.3$ & $3.1 \pm 1.5$ & $14.6 \pm 4.7$ \\
\hline Freshwater & $8.0 \pm 2.2$ & $1.5 \pm 0.8$ & $0.0 \pm 0.0$ & $0.0 \pm 0.0$ & $0.0 \pm 0.0$ & $6.7 \pm 2.2^{*}$ \\
\hline Average & $8.6 \pm 1.9$ & $2.5 \pm 0.5$ & $0.1 \pm 0.1$ & $05 . \pm 0.2$ & $2.2 \pm 0.7$ & $13.2 \pm 2.3$ \\
\hline
\end{tabular}


Table 3. Two-way mixed model ANOVA of arcsin-transformed data of the dependent variable of hatching success excluding hatchling death in incubation phases 1 and 2, where clutch is a random factor and treatment is a fixed factor. Significant differences are highlighted in bold

\begin{tabular}{|lccccc|}
\hline Effect & SS & df & MS & $F$ & $p$ \\
\hline Intercept (Fixed) & 40.14765 & 1 & 40.14765 & 268.8639 & $<0.0001$ \\
Treatment (Fixed) & $\mathbf{0 . 9 5 1 6 9}$ & $\mathbf{2}$ & $\mathbf{0 . 4 7 5 8 5}$ & $\mathbf{6 . 5 0 4 9}$ & $\mathbf{0 . 0 0 6 0 3}$ \\
Clutch (Random) & 1.64256 & 11 & 0.14932 & 2.0413 & 0.0743 \\
Treatment $\times$ Clutch & 1.60933 & 22 & 0.07315 & & \\
$\quad$ (Random) & & & & & \\
\hline
\end{tabular}

modelling, irrigation did not change the sex ratio outcome during our experimental period, but if we had started our experiment 2 wk earlier, the application of seawater would have changed the sex ratio outcome. This is assuming that nest temperatures decreased by $1.3^{\circ} \mathrm{C}$, as observed on day 18 of incubation.

\section{DISCUSSION}

\subsection{General findings}

We found that if sufficient volume of water is added in the form of artificial rain, irrigation using either freshwater or seawater can decrease sand temperature at nest depth by $1.3^{\circ} \mathrm{C}$, sufficient to reduce nest temperature into the male hatchling producing zone. Most importantly, we found that a one-off irrigation with seawater did not cause a decrease in hatching success as had previously been assumed.

\subsection{Irrigation regimes}

In our eggless experiments, irrigation altered temperature at nest depth, but not always in the way we anticipated. At Heron Island, the control temperatures were lower than any of the treatments, but experienced the same consistent warming trend as the experiment proceeded. This difference was probably due to a microclimate difference, with the controls experiencing more Pisonia tree shade than the treatment nests. With the exception of the $200 \mathrm{~mm}$ in $1 \mathrm{~d}$ regime, the irrigation regimes we used in our Heron Island eggless experiments resulted in an increase rather than a decrease in sand temperature at nest depth, a finding contradictory to our expectation. This finding is likely a consequence of the time of year when these trials were conducted. In early December on Heron Island, the sand temperature at nest depth is still increasing from winter tempera- tures (Fig. 4) (Booth \& Freeman 2006). During the austral summer, the sand close to the surface is warmer than the sand at nest depth (Booth \& Freeman 2006). In treatments where irrigation resulted in an increase in sand temperature at nest depth, the water applied absorbed heat from surface sand. As this heated water percolated downwards, the heat it was carrying was transferred to the sand below, causing an increased temperature at nest depth. However, when a larger volume of water was applied (200 $\mathrm{mm}$ in $1 \mathrm{~d}$ ), the water was still cooler than the sand at nest depth when it reached this depth as a result of the larger volume of water being able to absorb and mitigate the heat from the surface sand. This explains why only the irrigation regime with the largest volume of water resulted in a significant temperature decrease at nest depth. A similar finding was observed by Jourdan \& Fuentes (2015), with irrigation applied during daylight hours eliciting an increase in sand temperature at nest depth. These findings highlight the important interaction between water temperature and the volume of water applied when contemplating cooling nests using irrigation (Naro-Maciel et al. 1999, Lolavar \& Wyneken 2021).

On Panasesa Island, the control shade treatment temperature was lower than the control sun-exposed temperature $\left(\sim 0.3^{\circ} \mathrm{C}\right.$ difference), and within the shade and sun treatments, irrigated sand was cooler than dry sand $\left(\sim 0.2^{\circ} \mathrm{C}\right.$ difference). However, this decrease in sand temperature at nest depth is lower than the $1.0-2.0^{\circ} \mathrm{C}$ decrease generally reported for artificially shaded nests (Wood et al. 2014, Esteban et al. 2018, Reboul et al. 2021). Also, the sand temperature at nest depth started out warmer in the shaded treatment than in the unshaded treatment, but became cooler as the trial proceeded. These differences might be explained by subtle differences in the spatial variation in sand temperature before the shade structure was constructed on day 1 of temperature monitoring, and the decrease of temperatures in the shaded plot over the first $4 \mathrm{~d}$ before irrigation began can be explained by the addition of shade, because it takes several days for sand to cool once shade is provided (Esteban et al. 2018). A natural rainfall event totalling $65 \mathrm{~mm}$ occurred on the day that daily irrigation started, and combined with the $50 \mathrm{~mm}$ artificial rainfall, resulted in sand temperature in all regimes decreasing between $0.4^{\circ} \mathrm{C}$ and $0.7^{\circ} \mathrm{C}$ within $24 \mathrm{~h}$, with the biggest falls occurring in the shaded treatment, so a combination of shading and irrigation 
might be the best way to reduce sand temperatures. Seawater and freshwater irrigated sand experienced similar temperature decreases because of similar specific heats of freshwater and seawater (4182 versus $3850 \mathrm{~J} \mathrm{~K}^{-1} \mathrm{~kg}^{-1}$, respectively; Sharqawy et al. 2010). Even if irrigation is not successful in decreasing temperatures at nest depth enough to produce males, it may benefit embryos by increasing water content in dry sands (Hill et al. 2015 and see below).

Collecting seawater in the evening and allowing it to cool overnight before its application maximised the cooling capacity of the water. If the seawater had been applied to the sand immediately after collection, in all cases there would have been an increase in sand temperature at nest depth because the temperature of the seawater being applied $\left(27.9-30.7^{\circ} \mathrm{C}\right)$ would have been greater than the sand temperature at nest depth $\left(27.2-27.8^{\circ} \mathrm{C}\right)$. Therefore, irrigating nest areas early in the morning before sunrise, when the sand surface and water temperatures are lowest, would be the best strategy for creating maleproducing temperatures (Jourdan \& Fuentes 2015). The amount of cooling that irrigation can cause via the physical absorption of heat as water percolates down through sand is dependent on the heat capacitance of the sand, and the volume and temperature of the water applied. The heat capacitance of sand varies between 800 and $1632 \mathrm{~J} \mathrm{~K}^{-1} \mathrm{~kg}^{-1}$ depending on its moisture content (Hamdhan \& Clarke 2010), and the heat capacitance of water varies between $4182 \mathrm{~J}$ $\mathrm{K}^{-1} \mathrm{~kg}^{-1}$ for freshwater and $3850 \mathrm{~J} \mathrm{~K}^{-1} \mathrm{~kg}^{-1}$ for seawater (Sharqawy et al. 2010). Therefore, the greater the volume of water and the lower the temperature of the water, the greater the cooling effect. During the nesting season, seawater temperature close to the shore (at a depth of $1 \mathrm{~m}$ ) is typically in the range of $25-31.5^{\circ} \mathrm{C}$ (AIMS 2020), which is not much cooler than control temperatures at nest depth (typically $28-32^{\circ} \mathrm{C}$ ). Hence, a relatively large volume of seawater will be needed to drop nest temperature significantly. In contrast, the water temperature of rainfall is most likely significantly cooler $\left(18-22^{\circ} \mathrm{C}\right)$, meaning a smaller volume of rainwater is needed to produce an equivalent amount of cooling in comparison to seawater as a result of the difference in temperature.

\subsection{Irrigation of green turtle eggs}

Marine turtle embryonic development is affected by water availability (Bustard \& Greenham 1968, McGehee 1990), and high salinity may cause egg dehydration (Ackerman 1997). However, incubating marine turtles can survive seawater inundation from large tides (Foley et al. 2006), and can survive total immersion in seawater for up to $6 \mathrm{~h}$ if immersion occurs outside of the first and last weeks of incubation (Limpus et al. 2020). Consequently, we anticipated that a one-off exposure to relatively intense irrigation with both freshwater and seawater would not cause an increase in embryo mortality. We found that hatching success tended to be greater in seawater irrigated eggs and significantly greater in freshwater irrigated eggs compared to un-irrigated control eggs. The hatching success of clutches in the control treatment was considerably lower than that found previously for Heron Island $(84.1 \%$; Limpus \& Fien 2009). This finding may be related to the exceptionally dry sand conditions at Heron Island during the 2019-2020 marine turtle nesting season, causing the control embryos to become dehydrated as incubation progressed (Ackerman 1997). In pliableshelled eggs, such as those laid by marine turtles, the eggshell is relatively permeable to water exchange between the embryo and the nest, and so the water potential of the incubating substrate is particularly important to embryonic development and hatching success, with dry substrate causing water loss from the egg and increased embryo mortality (reviewed in Ackerman 1991, Packard 1991). The mortality rate of embryos was greater in the final phase of development, potentially caused by desiccation prior to hatching (McGehee 1990) or by temperatures in excess of $36^{\circ} \mathrm{C}$ during the final $4 \mathrm{~d}$ of incubation, which is above the thermal tolerance of most marine turtle species (Ackerman 1997). Increased late-stage embryo death correlated with high nest temperatures is frequently reported in marine turtle nests (Bladow \& Milton 2019). A combination of dehydration and high temperatures may have combined to cause the relatively high mortality of control embryos we observed (Santidrián Tomillo et al. 2012).

Importantly, one-off seawater irrigation near the time of the SDP did not result in a decrease in embryo survival. The most probable reason why seawater exposure did not cause an increase in embryonic mortality in our experiments but caused rapid dehydration and embryo death in Bustard \& Greenham's (1968) experiments is due to a difference in experimental design. In Bustard \& Greenham's (1968) experiments, each egg was buried completely surrounded by sand, so the entire egg surface was available for water exchange with seawater, and other eggs within the clutch were not able to buffer the water lost to the surrounding sand. However, in our experiment, eggs were buried in entire clutches, 
and in such cases only the outer most eggs are in direct contact with the sand, and the inner eggs are in contact with each other. Hence, in our experiments, only the outermost layer of eggs was exposed to the osmotically stressful sand, and these eggs could also exchange water with the other eggs they were in contact with to buffer the osmotic water loss they might incur. So, in natural nests, because of the large volume of eggs and the fact that sand does not always penetrate to the centre of the nest, a one-off exposure to seawater irrigation does not necessarily result in a decrease in hatching success. However, we did observe a tendency for slightly greater hatching success in freshwater irrigated eggs compared to seawater irrigated eggs, and this might be explained by some of the peripherally located eggs in seawater nests experiencing fatal dehydration due to osmotic water loss to the surrounding seawater-treated sand.

\subsection{Predictive sex-ratio modelling}

On Heron Island, the one-off irrigation event caused nest temperature to drop by $\sim 1.3^{\circ} \mathrm{C}$, but this cooling event was short-lived, with nest temperatures returning to baseline temperatures within $4 \mathrm{~d}$. Depending on the starting nest temperature, which at our site is date dependent, because the sand is still warming up early in the nesting season (Booth \& Freeman 2006), this cooling event could result in a significant increase in male hatchling production if it occurred during the SDP. Modelling sex ratios using temperature traces resulted in a $0 \%$ chance of male production in all our experimental treatments, if the SDP started on day 18 of incubation. In this case, irrigation intervention would have had no effect on male hatchling production because the brief cooling event was not enough to decrease nest temperature to male-producing temperatures for long enough. In contrast, if our clutches of eggs had been laid $10 \mathrm{~d}$ earlier, the SDP would have started on the equivalent of day 10 of our temperature traces, and the predicted outcome would be a majority of male hatchlings in the freshwater and seawater treatments, with a very small percentage of males produced in the control. In this case, the irrigation intervention would have greatly increased male hatchling production. This highlights the importance of the timing of temperature drops during development in order to increase male production. Recent work has also indicated that short periods (3-10 d) of temperature drops to male-producing temperatures can result in increased male hatchling production even when the- oretical calculations predict all female hatchlings (Woolgar et al. 2013, Porter 2020). Hence, it is likely that short-term drops in nest temperature caused by one-off irrigation events are probably more effective at increasing male production than traditional modelling indicates. Sex-ratio predictive modelling assumes that laboratory data combined with theory accurately portray what occurs in natural nests, but studies that verify modelling with actual nest sexratio data are needed for marine turtles. Indeed, the one study that has examined equivalent data in a freshwater turtle (Chrysemys picta) indicated that sex-ratio modelling based on nest temperature traces is a poor predictor of actual hatchling sex ratios (Carter et al. 2019).

\subsection{Management implications and conclusions}

Our experiments confirm the findings of previous irrigation studies (Patino-Martinez et al. 2012, Hill et al. 2015, Jourdan \& Fuentes 2015) that watering sand can decrease the sand temperature at nest depth, but also show that the amount of cooling is dependent on the volume of water applied. Simple theoretical analysis also indicates that the colder the water applied, the greater the amount of cooling at nest depth. This cooling could induce male production, and one-off cooling events where nest cooling lasts for a relatively short period are likely to increase male hatchling production (Woolgar et al. 2013, Porter 2020). Although we were not able to directly measure sex ratios in this study, it would greatly benefit future investigations. We report a novel finding that embryonic mortality did not increase after a one-off application of seawater near the start of the SDP. If this finding can be verified in subsequent studies, it has important management implications because it indicates that one-off irrigation of marine turtle nests with seawater can induce male hatchling production without significantly impacting embryonic mortality. At marine turtle nesting beaches where high sand temperatures are causing the feminisation of hatchlings and where shading and freshwater irrigation are not practical, a one-off application of seawater should be seriously considered as a management strategy to increase male hatchling production whilst maintaining high hatching success.

Acknowledgements. We extend our gratitude and thanks to Koala.com for funding this project. We also thank the scientific officers Megan Skelton, Adriana Campili and Kirsten Slemint at Heron Island Research Station for their assistance while we visited the station, and the conservation rangers 
and interns at the Conflict Islands Conservation Initiative for assisting with data collection and building shade structures.

\section{LITERATURE CITED}

Ackerman RA (1991) Physical factors affecting the water exchange of buried reptile eggs. In: Deeming DC, Ferguson MWJ (eds) Egg incubation: its effects on embryonic development in birds and reptiles. Cambridge University Press, Cambridge, p 193-212

Ackerman RA (1997) The nest environment and the embryonic development of sea turtles. In: Lutz PL, Musick JA (eds) The biology of sea turtles, Vol 1. CRC Press, Boca Raton, FL, p 83-106

Alfaro-Shigueto J, Mangel JC, Darquea J, Donoso M, Baquero A, Doherty PD, Godley BJ (2018) Untangling the impacts of nets in the southeastern Pacific: rapid assessment of marine turtle bycatch to set conservation priorities in small-scale fisheries. Fish Res 206:185-192

Australian Institute of Marine Science (AIMS) (2020) Seawater temperature logger data at Heron Island, Great Barrier Reef from 24 Nov 1995 to 20 Jun 2020. https:// apps.aims.gov.au/metadata/view/446a0e73-7c30-47129ddb-ba1fc29b8b9a (accessed 2 September 2020)

Bladow RA, Milton S (2019) Embryonic mortality in green (Chelonia mydas) and loggerhead (Caretta caretta) sea turtle nests increases with cumulative exposure to elevated temperatures. J Exp Mar Biol Ecol 518:151180

Blanck CE, Sawyer RH (1981) Hatchery practices in relation to early embryology of the loggerhead sea turtle, Caretta caretta (Linne). J Exp Mar Biol Ecol 49:163-177

* Blechschmidt J, Wittmann MJ, Blüml C (2020) Climate change and green sea turtle sex ratio - preventing possible extinction. Genes 11:588

Booth DT, Astill K (2001) Incubation temperature, energy expenditure and hatchling size in the green turtle (Chelonia mydas), a species with temperature-sensitive sex determination. Aust J Zool 49:389-396

Booth DT, Freeman C (2006) Sand and nest temperatures and an estimate of hatchling sex ratio from the Heron Island green turtle (Chelonia mydas) rookery, Southern Great Barrier Reef. Coral Reefs 25:629-633

Booth DT, Burgess E, McCosker J, Lanyon JM (2004) The influence of incubation temperature on post-hatching fitness characteristics of turtles. Int Congr Ser 1275: 226-233

Broderick AC, Godley BJ, Reece S, Downie JR (2000) Incubation periods and sex ratios of green turtles: highly female biased hatchling production in the eastern Mediterranean. Mar Ecol Prog Ser 202:273-281

* Burgess E, Booth DT, Lanyon JM (2006) Swimming performance of hatchling green turtles is affected by incubation temperature. Coral Reefs 25:341-349

Bustard HR, Greenham P (1968) Physical and chemical factors affecting hatching in the green sea turtle, Chelonia mydas (L.). Ecology 49:269-276

Carter AL, Bodensteiner BL, Iverson JB, Milne-Zelman CL and others (2019) Breadth of the thermal response captures individual and geographic variation in temperature-dependent sex determination. Funct Ecol 33: 1928-1939

Caut S, Guirlet E, Girongot M (2010) Effect of tidal overwash on the embryonic development of leatherback turtles in French Guiana. Mar Environ Res 69:254-261
Chen IC, Hill JK, Ohlemüller R, Roy DB, Thomas CD (2011) Rapid range shifts of species associated with high levels of climate warming. Science 333:1024-1026

* Descamps S, Aars J, Fuglei E, Kovacs KM and others (2017) Climate change impacts on wildlife in a High Arctic archipelago - Svalbard, Norway. Glob Change Biol 23: 490-502

Dunstan AJ, Robertson K (2017) Raine Island Recovery Project: 2016-17 Season technical report to the Raine Island Scientific Advisory Committee and Raine Island Reference Group. Queensland Government Department of National Parks, Sport and Racing, Brisbane

Esteban N, Laloë JO, Mortimer JA, Guzman AN, Hays GC (2016) Male hatchling production in sea turtles from one of the world's largest marine protected areas, the Chagos Archipelago. Sci Rep 6:20339

Esteban N, Laloë JO, Kiggen FS, Ubels SM and others (2018) Optimism for mitigation of climate warming impacts for sea turtles through nest shading and relocation. Sci Rep 8:17625

Foley AM, Peck SA, Harman GR (2006) Effects of sand characteristics and inundation on the hatching success of loggerhead sea turtle (Caretta caretta) clutches on lowrelief mangrove islands in southwest Florida. Chelonian Conserv Biol 5:32-41

Fuentes MMPB, Hamann M, Limpus CJ (2010) Past, current and future thermal profiles of green turtle nesting grounds: implications from climate change. J Exp Mar Biol Ecol 383:56-64

Fuentes MM, Gredzens C, Bateman BL, Boettcher R and others (2016) Conservation hotspots for marine turtle nesting in the United States based on coastal development. Ecol Appl 26:2708-2719

*Georges A, Limpus CJ, Stoutjesdijk C (1994) Hatchling sex in the marine turtle Caretta caretta is determined by proportion of development at a temperature, not daily duration of exposure. J Exp Zool 270:432-444

Hamann M, Limpus CJ, Read MA (2007) Vulnerability of marine reptiles to climate change in the Great Barrier Reef. In: Johnson, JE, Marshall, PA (eds) Climate change and the Great Barrier Reef: a vulnerability assessment. Great Barrier Reef Marine Park Authority and Australian Greenhouse Office, Townsville, p 465-497

Hamdhan IN, Clarke BG (2010) Determination of thermal conductivity of coarse and fine sand soils. In: Proceedings of World Geothermal Congress, Bonn, p 1-7

* Hawkes LA, Broderick AC, Godfrey MH, Godley BJ (2009) Climate change and marine turtles. Endang Species Res $7: 137-154$

* Hawkes LA, McGowan A, Godley BJ, Gore S and others (2013) Estimating sex ratios in Caribbean hawksbill turtles: testosterone levels and climate effects. Aquat Biol 18:9-19

Hays GC, Ashworth JS, Barnsley MJ, Broderick AC, Emery DR, Godley BJ, Henwood A (2001) The importance of sand albedo for the thermal conditions on sea turtle nesting beaches. Oikos 93:87-94

*Hays GC, Mazaris AD, Schofield G (2014) Different male vs. female breeding periodicity helps mitigate offspring sex ratio skews in sea turtles. Front Mar Sci 1:43

Higginson J, Vasquez F (1989) Hatchery design and the production of female hatchlings. Mar Turtle Newsl 44:7-12

*Hill JE, Paladino FV, Spotila JR, Tomillo PS (2015) Shading and watering as a tool to mitigate the impacts of climate change in sea turtle nests. PLOS ONE 10:e0129528 
Houghton JDR, Myers AE, Lloyd C, King RS, Isaacs C, Hays GC (2007) Protracted rainfall decreases temperature within leatherback turtle (Dermochelys coriacea) clutches in Grenada, West Indies: ecological implications for a species displaying temperature dependent sex determination. J Exp Mar Biol Ecol 345:71-77

IPCC (2019) Summary for Policymakers. In: Shukla PR, Skea J, Calvo Buendia E and others (eds) Climate change and land: an IPCC special report on climate change, desertification, land degradation, sustainable land management, food security, and greenhouse gas fluxes in terrestrial ecosystems. In press

Janzen FJ (1994) Climate change and temperaturedependent sex determination in reptiles. Proc Natl Acad Sci USA 91:7487-7490

Jensen MP, Allen CD, Eguchi T, Bell IP and others (2018) Environmental warming and feminization of one of the largest sea turtle populations in the world. Curr Biol 28:154-159

Jourdan J, Fuentes MMPB (2015) Effectiveness of strategies at reducing sand temperature to mitigate potential impacts from changes in environmental temperature on sea turtle reproductive output. Mitig Adapt Strategies Glob Change 20:121-133

*aloë JO, Esteban N, Berkel J, Hays GC (2016) Sand temperatures for nesting sea turtles in the Caribbean: implications for hatchling sex ratios in the face of climate change. J Exp Mar Biol Ecol 474:92-99

Laloë JO, Tedeschi JN, Booth DT, Bell I, Dunstan A, Reina RD, Hays GC (2021) Extreme rainfall events and cooling of sea turtle clutches: implications in the face of climate warming. Ecol Evol 11:560-565

Limpus CJ (2008a) A biological review of Australian marine turtle species. 1. Loggerhead turtle, Caretta caretta (Linneaus). Queensland Government Environmental Protection Agency, Brisbane

Limpus CJ (2008b) A biological review of Australian marine turtle species. 2. Green turtle, Chelonia mydas (Linnaeus). Queensland Government Environmental Protection Agency, Brisbane

Limpus CJ, Fien L (2009) A biological review of Australian marine turtles. Queensland Government Environmental Protection Agency, Brisbane

*impus CJ, Miller JD, Pfaller JB (2020) Flooding induced mortality of loggerhead sea turtle eggs. Wildl Res 48: 142-151

Lolavar A, Wyneken J (2015) Effect of rainfall on loggerhead turtle nest temperatures, sand temperatures and hatchling sex. Endang Species Res 28:235-247

* Lolavar A, Wyneken J (2021) Effects of supplemental watering on loggerhead (Caretta caretta) nests and hatchlings. J Exp Mar Biol Ecol 534:151476

Martin RE (1996) Storm impacts on loggerhead turtle reproductive success. Mar Turtle Newsl 73:10-12

* Mason LR, Green RE, Howard C, Stephens PA and others (2019) Population responses of bird populations to climate change on two continents vary with species' ecological traits but not with direction of change in climate suitability. Clim Change 157:337-354

McGehee MA (1990) Effects of moisture on eggs and hatchlings of loggerhead sea turtles (Caretta caretta). Herpetologica 46:251-258

Miller JD, Limpus CJ (1981) Incubation period and sexual differentiation in the green turtle Chelonia mydas. In: Banks C, Martin A (eds) Proceedings of the Melbourne
Herpetological Symposium. The Zoological Board of Victoria, Parkville, p 66-73

Miller JD, Mortimer JA, Limpus CJ (2017) A field key to the developmental stages of marine turtles (Cheloniidae) with notes on the development of Dermochelys. Chelonian Conserv Biol 16:111-122

Naro-Maciel E, Morsovsky N, Marcovaldi MA (1999) Thermal profiles of sea turtle hatcheries and nesting areas at Praia do Forte, Brazil. Chelonian Conserv Biol 3:407-413

Nicotra AB, Atkin OK, Bonser SP, Davidson AM and others (2010) Plant phenotypic plasticity in a changing climate. Trends Plant Sci 15:684-692

Packard GC (1991) The physiological and ecological importance of water to wembryos of oviparous reptiles. In: Deeming DC, Ferguson MWJ (eds) Egg incubation: its effects on embryonic development in birds and reptiles. Cambridge University Press, Cambridge, p 213-228

*Packard GC (1999) Water relations of chelonian eggs and embryos: is wetter better? Am Zool 39:289-303

* Patino-Martinez J, Marco A, Quiñones L, Hawkes L (2012) A potential tool to mitigate the impacts of climate change to the Caribbean leatherback sea turtle. Glob Change Biol 18:401-411

*Pike DA, Stiner JC (2007) Sea turtle species vary in their susceptibility to tropical cyclones. Oecologia 153: 471-478

*Poloczanska ES, Limpus CJ, Hays GC (2009) Vulnerability of marine turtles to climate change. Adv Mar Biol 56: $151-211$

* Poloczanska ES, Brown CJ, Sydeman WJ, Kiessling W and others (2013) Global imprint of climate change on marine life. Nat Clim Change 3:919-925

Porter E (2020) Influence of short-term temperature drops on sex determination in sea turtles. Unpublished Honours thesis, School of Biological Sciences, The University of Queensland

* Reboul I, Booth D, Rusli U (2021) Artificial and natural shade: implications for green turtle (Chelonia mydas) rookery management. Ocean Coast Manage 204:105521

* Reusch TB (2014) Climate change in the oceans: evolutionary versus phenotypically plastic responses of marine animals and plants. Evol Appl 7:104-122

* Rivas ML, Spinola M, Arrieta H, Faife-Cabrera M (2018) Effect of extreme climatic events resulting in prolonged precipitation on the reproductive output of sea turtles. Anim Conserv 21:387-395

* Santidrián Tomillo PS, Saba VS, Blanco GS, Stock CA, Paladino FV, Spotila JR (2012) Climate driven egg and hatchling mortality threatens survival of Eastern Pacific leatherback turtles. PLOS ONE 7:e37602

* Schuyler QA, Wilcox C, Townsend KA, WedemeyerStrombel KR, Balazs G, van Sebille E, Hardesty BD (2016) Risk analysis reveals global hotspots for marine debris ingestion by sea turtles. Glob Change Biol 22: 567-576

Seebacher F, White CR, Franklin CE (2015) Physiological plasticity increases resilience of ectothermic animals to climate change. Nat Clim Change 5:61-66

Sharqawy MH, Lienhard JH, Zubair SM (2010) Thermophysical properties of seawater: a review of existing correlations and data. Desalination Water Treat 16:354-380

Staines MN, Booth DT, Limpus CJ (2019) Microclimatic effects on the incubation success, hatchling morphology and locomotor performance of marine turtles. Acta Oecol $97: 49-56$ 
Staines MN, Booth DT, Hof CAM, Hays GC (2020) Impact of heavy rainfall events and shading on the temperature of sea turtle nests. Mar Biol 167:1-11

Standora EA, Spotila JR (1985) Temperature dependent sex determination in sea turtles. Copeia 1985:711-722

Stelfox M, Burian A, Shanker K, Rees AF and others (2020) Tracing the origin of olive ridley turtles entangled in ghost nets in the Maldives: a phylogeographic assessment of populations at risk. Biol Conserv 245:108499

Tanner CE, Marco A, Martins S, Abella-Perez E, Hawkes LA (2019) Highly feminised sex-ratio estimations for the world's third-largest nesting aggregation of loggerhead sea turtles. Mar Ecol Prog Ser 621:209-219

Tilley D, Ball S, Ellick J, Godley BJ, Weber N, Weber SB, Broderick AC (2019) No evidence of fine scale thermal adaptation in green turtles. J Exp Mar Biol Ecol 514-515: 110-117

Tomlinson PB (2004) The biology of mangroves. Cambridge University Press, Cambridge

Urban MC, Richardson JL, Freidenfelds NA (2014) Plasticity and genetic adaptation mediate amphibian and reptile responses to climate change. Evol Appl 7:88-103

Varela MR, Patrício AR, Anderson K, Broderick AC and others (2019) Assessing climate change associated sealevel rise impacts on sea turtle nesting beaches using drones, photogrammetry and a novel GPS system. Glob Change Biol 25:753-762

Villa CA, Bell I, Hof CM, Limpus CJ, Gaus C (2019) Elucidating temporal trends in trace element exposure of

Editorial responsibility: Peter Corkeron,

Woods Hole, Massachusetts, USA

Reviewed by: C. Gatto and 2 anonymous referees green turtles (Chelonia mydas) using the toxicokinetic differences of blood and scute samples. Sci Total Environ 651:2450-2459

Visser ME (2008) Keeping up with a warming world; assessing the rate of adaptation to climate change. Proc Biol Sci 275:649-659

Wibbels T (2003) Critical approaches to sex determination in sea turtles. In: Lutz PL, Musick JA, Wyneken J (eds) The biology of sea turtles, Vol II. CRC Press, Boca Raton FL, p 103-134

WWitt MJ, Hawkes LA, Godfrey MH, Godley BJ, Broderick AC (2010) Predicting the impacts of climate change on a globally distributed species: the case of the loggerhead turtle. J Exp Biol 213:901-911

*Wood A, Booth DT, Limpus CJ (2014) Sun exposure, nest temperature and loggerhead turtle hatchlings: Implications for beach shading management strategies at sea turtle rookeries. J Exp Mar Biol Ecol 451:105-114

Woolgar L, Trocini S, Mitchell N (2013) Key parameters describing temperature-dependent sex determination in the southernmost population of loggerhead sea turtles. J Exp Mar Biol Ecol 449:77-84

Wyneken J, Burke TJ, Salmon M, Pedersen DK (1988) Egg failure in natural and relocated sea turtle nests. J Herpetol 22:88-96

Yntema CL, Mrosovsky N (1980) Sexual differentiation in hatchling loggerheads (Caretta caretta) incubated at different controlled temperatures. Herpetologica 36: $33-36$

Submitted: October 23, 2020

Accepted: April 7, 2021

Proofs received from author(s): June 7, 2021 